Eur. J. Clin. Chem. Clin. Biochem.

Vol. 31, 1993, pp. 575-578

(C) 1993 Walter de Gruyter \& Co.

Berlin - New York

\title{
On the Degree of Platelet, Coagulation and Fibrinolysis Activation after Cerebral Infarction and Cerebral Haemorrhage and the Clinical Outcome
}

\author{
By J.W. J. van Wersch ${ }^{1}$ and C. L. Franke \\ ${ }^{1}$ Haematological Laboratory \\ 2 Department of Neurology \\ De Wever Hospital, Heerlen, The Netherlands
}

(Received March 5/June 22, 1993)

\begin{abstract}
Summary: Thrombocytic, haemostatic and fibrinolytic quantities were investigated in 47 patients with cerebral infarction and 34 patients with cerebral haemorrhage. Sixteen of the infarction patients and ten patients of the haemorrhage group were on acetylsalicylic acid medication. Of the remaining 55 patients without acetylsalicylic medication $21 / 31=67.7 \%$ of the patients in the infarction group and $9 / 24=37.5 \%$ of the patients in the bleeding group had unphysiologically enhanced ADP-induced platelet aggregation. With regard to the coagulation and fibrinolysis markers no significant differences were found between the two groups. In both groups, coagulation activity markers (fibrin monomer and thrombin-antithrombin III), as well as Ddimers were significantly higher than in controls in a high proportion of cases. In 5/47 of the infarction patients and in 3/34 of the haemorrhage patients the fibrin monomer levels were elevated to such an extent, that it can be considered as low grade disseminated intravascular coagulation.
\end{abstract}

In the cerebral haemorrhage group, $80.3 \%$ of the patients who subsequently died showed a significantly enhanced fibrin monomer concentration, compared with $28.6 \%$ of those who survived. The corresponding frequencies for D-dimer were $100 \%$ compared with $66.7 \%$.

In the cerebral infarction group, the only analytical quantity showing a significant difference between patients with a fatal outcome and those with a non-fatal outcome was ADP $(2 \mu \mathrm{mol} / \mathrm{l})$ induced platelet aggregation (83.3\% in the fatal group, $40.0 \%$ in the non-fatal group).

\section{Introduction}

Cerebral infarction and cerebral haemorrhage are events which may be accompanied by coagulation activation and (reactive) fibrinolysis. The clinical significance and relevance of coagulation and platelet abnormalities $(1,2)$ on the one hand and of coagulation and fibrinolysis factors (3) on the other hand have been studied earlier. None of the factors studied so far has shown a significant difference from normal in cases of cerebral infarction and cerebral bleeding.
In recent years a number of new, more sensitive quantities have become available for testing for clotting and fibrinolysis: fibrin monomers (4), thombin-antithrombin-III complexes (5) and D-dimers (6). These quantities may be useful for sensitive monitoring of the course of the disease, for the better follow-up of the therapy and the possible estimation of the prognosis.

Aim of this study was to get more insight in the extent of platelet coagulation and fibrinolysis activation after recent cerebral bleeding and infarction. 
Tab. 1. Basic data of the patients.

\begin{tabular}{|c|c|c|c|c|}
\hline \multirow[b]{2}{*}{ Mean age } & \multicolumn{2}{|c|}{$\begin{array}{l}\text { Cerebral infarction } \\
(\mathrm{n}=47)\end{array}$} & \multicolumn{2}{|c|}{$\begin{array}{l}\text { Cerebral haemorrhage } \\
(\mathrm{n}=34)\end{array}$} \\
\hline & \multicolumn{2}{|c|}{$65.6 \pm 13.6(\mathrm{SD})$ years } & \multicolumn{2}{|c|}{$71 ! 0 \pm 11.6(\mathrm{SD})$ years } \\
\hline & Number & $\%$ & Number & $\%$ \\
\hline $\begin{array}{l}\text { Males } \\
\text { Females } \\
\text { Diabetes mellitus } \\
\text { History of hypertension } \\
\text { Patients on acetylsalicylic acid }\end{array}$ & $\begin{array}{l}21 \\
26 \\
13 \\
15 \\
16\end{array}$ & $\begin{array}{l}44.6 \\
55.4 \\
27.7 \\
31.9 \\
34.0\end{array}$ & $\begin{array}{r}20 \\
14 \\
0 \\
14 \\
10\end{array}$ & $\begin{array}{c}58.8 \\
41.2 \\
0 \\
41.1 \\
29.4\end{array}$ \\
\hline
\end{tabular}

\section{Patients}

Venous blood samples were collected from 81 patients, 47 with cerebral infarction ( 21 males, 26 females, mean age \pm 2 SD: $65.5 \pm 13.6$; range $39-87$ years) and 34 with cerebral bleeding (20 males, 14 females, mean age \pm 2 SD: $71.0 \pm 11.6$; range 42-90 years). The basic data of the patients are summarized in table 1. Blood samples were taken immediately after admission to the Department of Neurology and before any therapeutic measures. The documentable day of the ictus was one to eleven days previously (mean 3.3 days).

All patients had computer tomography (CT-scanning) to confirm the diagnosis. In the group of patients with cerebral haemorrhage the extent of the bleeding was estimated from the computer tomography pictures. The sizes displayed a wide range from 1.5 to $104 \mathrm{ml}$ (median $11 \mathrm{ml}$ ). There was no correlation between the extent of bleeding and the extent of coagulation activation.

The size of the brain lesion in the infarction group is difficult to assess with computer tomography. The most likely stroke mechanism in the infarction patient group was atherothrombotic in 30 of the 47, cardioembolic in 10 and lacunar in 7 patients. No patient exhibited a primary haemostatic defect nor was any patient known to have a familial history of thrombosis.

Laboratory reference values were obtained from 50 subjectively healthy volunteers, age range 24 to 50 years. The mean values \pm 2 SD were taken as the reference ranges. The control group was age and sex matched $(n=135$, age range $24-90$ years, mean 55.3 years) and consisted of subjectively healthy patients visiting the hospital pre-operatively before minor elective surgical treatment. The usual pre-operative laboratory investigations were normal. The participants were free of acute and chronic disease. Subjects with heart disease, known cancer or previous histories of thrombotic events or haematoma were excluded. Controls were not taking medication known to interfere with coagulation.

\section{Samples}

The blood samples were drawn between 8.30 and $9.00 \mathrm{a} . \mathrm{m}$. Citrated plasma was prepared by centrifugation of nine volumes of freshly drawn blood with one volume of trisodium citrate $(0.11 \mathrm{~mol} / \mathrm{l})$ for $10 \mathrm{~min}$ at $25^{\circ} \mathrm{C}(1600 \mathrm{~g})$. The plasmas were stored at $-70^{\circ} \mathrm{C}$ in plastic tubes and thawed with tap water for $5 \mathrm{~min}$ before use.

The platelet aggregation tests were performed on platelet-rich plasma which was prepared by immediate centrifugation of citrated blood (prepared as described above) at $200 \mathrm{~g}$ for 10 minutes at room temperature. After gentle aspiration of the platelet-rich plasma, using a plastic pipette, the remaining blood was centrifuged at $2000 \mathrm{~g}$ for $10 \mathrm{~min}$ at room temperature; the resulting platelet-poor plasma was aspirated and subsequently centrifuged at $10000 \mathrm{~g}$ at $4{ }^{\circ} \mathrm{C}$ for $10 \mathrm{~min}$ to obtain platelet- free plasma. Platelet-rich plasma and platelet-free plasma were used for standardization of the end concentration of the platelet count in the test.

The ADP-induced aggregations were performed at a platelet concentration of $200 \times 10^{9} / 1$.

\section{Methods}

The chromogenic Coa-set fibrin monomer test of Kabi Vitrum Diagnostica was used for the fibrin monomer determinations. For the thrombin-antithrombin III determinations we used an Elisa test kit from Behring (Behring Corp, Marburg, Germany). The fibrin degradation products were determined with the $D$ dimer test (Boehringer Mannheim, Mannheim, Germany). The D-dimer test is a specific Elisa test for the determination of degradation products of cross-linked fibrin only and not of fibrinogen. The ADP-induced platelet aggregations were measured by a turbidimetric method using a Daiichi dual channel aggregation device (Daiichi Kyoto, Japan). The link between test concentrations and results is given in table 2.

\section{Statistical analysis}

For the comparison of the patient groups with each other and of each patient group with the reference group, the MannWhitney-U test was employed. The $\chi^{2}$-test was employed to test the percentage difference between the various methods.

\section{Results}

Table 2 summarizes the results and criteria for normality of the different aggregation tests carried out in this study. We found enhanced $2 \cdot 10^{-6} \mathrm{~mol} / \mathrm{l}$ ADPinduced platelet aggregations in $21 / 31$ of the infarction patients and in $9 / 24$ of the bleeding patients.

The clotting and fibrinolysis quantities did not differ significantly between the groups with cerebral haemorrhage and with cerebral infarction (results not shown).

Comparison of the analytical quantities of both patient groups with the upper limit of the reference ranges (tab. 3) showed a high frequency of elevated concentrations for fibrin monomer (61.7 and 44.1), for thrombin-antithrombin III $(57.4 \%$ and $41.2 \%)$ and for D-dimer (76.6\% and 79.4$)$ for cerebral in- 
farction and haemorrhage respectively. Comparison of the median values of these quantities of both patient groups with the control group showed that the differences for all three quantities were highly significant.
In table 4 the patient groups are subdivided according to the clinical outcome (fatal, non-fatal) and the extent of the coagulation, fibrinolysis and platelet activation (i.e. concentrations above the upper limit of the respective reference ranges). The different fre-

Tab. 2. The criteria for normality and the results of the different types of aggregation tests.

\begin{tabular}{|c|c|c|c|c|}
\hline \multirow{3}{*}{ Aggregation inducer } & \multicolumn{2}{|c|}{ Criteria for normality } & & \\
\hline & \multirow{2}{*}{$\begin{array}{l}\text { Aggregation } \\
\text { pattern }\end{array}$} & \multirow{2}{*}{$\begin{array}{l}\text { Aggregation } \\
\text { maximum } \\
\text { (change in light } \\
\text { transmission) }\end{array}$} & \multicolumn{2}{|c|}{ Abnormal number } \\
\hline & & & $\begin{array}{l}\text { Cerebral } \\
\text { infarction }\end{array}$ & $\begin{array}{l}\text { Cerebral } \\
\text { haemorrhage }\end{array}$ \\
\hline \multicolumn{5}{|l|}{$\mathrm{ADP}(\mu \mathrm{mol} / \mathrm{l})$} \\
\hline 0.2 & aggregation absent & 0 & $2 / 31=6.5 \%$ & $2 / 24=8.3 \%$ \\
\hline \multicolumn{5}{|l|}{$\mathrm{ADP}(\mu \mathrm{mol} / \mathrm{l})$} \\
\hline 2 & reversible & $\leq 50$ & $21 / 31=67.7 \%$ & $9 / 24=37.5 \%$ \\
\hline \multicolumn{5}{|l|}{$\mathrm{ADP}(\mu \mathrm{mol} / \mathrm{l})$} \\
\hline 10 & non reversible & $>50$ & $0 / 31=0 \%$ & $1 / 24=4.2 \%$ \\
\hline
\end{tabular}

Tab. 3. Coagulation and fibrinolysis markers of the patient groups in comparison with the control group ( $\mathrm{n}=135)$. (* $M a n n-$ Whitney-U test). IQR = interquartile range.

\begin{tabular}{|c|c|c|c|c|c|c|c|}
\hline \multirow[t]{2}{*}{$\begin{array}{l}\text { Analytes } \\
\text { (reference ranges) }\end{array}$} & \multirow{2}{*}{$\begin{array}{l}\text { Cerebral } \\
\text { infarction } \\
(\mathrm{n}=47) \\
\text { Median } \\
(\mathrm{IQR})\end{array}$} & \multirow{2}{*}{$\begin{array}{l}\text { Cerebral } \\
\text { haemorrhage } \\
(\mathrm{n}=34) \\
\text { Median } \\
(\mathrm{IQR})\end{array}$} & \multirow{2}{*}{$\begin{array}{l}\text { Control } \\
\text { group } \\
(\mathrm{n}=135) \\
\text { Median } \\
(\mathrm{IQR})\end{array}$} & \multicolumn{2}{|c|}{$\begin{array}{l}\text { Significance } \\
\text { p-value }\end{array}$} & \multicolumn{2}{|c|}{$\begin{array}{l}\text { Patients exceeding the upper } \\
\text { reference limit of laboratory } \\
\text { reference range }\end{array}$} \\
\hline & & & & $\begin{array}{l}\text { Cerebral } \\
\text { infarction }\end{array}$ & $\begin{array}{l}\text { Cerebral } \\
\text { haemorrhage }\end{array}$ & $\begin{array}{l}\text { Cerebral } \\
\text { infarction }\end{array}$ & $\begin{array}{l}\text { Cerebral } \\
\text { haemorrhage }\end{array}$ \\
\hline $\begin{array}{l}\text { Fibrin monomer } \\
\qquad(8.4-13.2 \mathrm{nmol} / \mathrm{l})\end{array}$ & $\begin{array}{l}14.3 \\
(8.5)\end{array}$ & $\begin{array}{c}12.2 \\
(5.0)\end{array}$ & $\begin{array}{c}10.5 \\
(2.0)\end{array}$ & $<0.001 *$ & $<0.01 *$ & $29 / 47$ & $15 / 34$ \\
\hline $\begin{array}{l}\text { Thrombin-antithrombin } \\
\text { III complex } \\
\quad(1.0-4.1 \mu \mathrm{g} / \mathrm{l})\end{array}$ & $\begin{array}{c}5.4 \\
(6.7)\end{array}$ & $\begin{array}{c}3.2 \\
(6.9)\end{array}$ & $\begin{array}{c}2.3 \\
(1.4)\end{array}$ & $<0.001^{*}$ & $<0.01 *$ & $27 / 47$ & $14 / 34$ \\
\hline $\begin{array}{l}\text { D-dimer } \\
\quad(0-450 \mu \mathrm{g} / \mathrm{l})\end{array}$ & $\begin{array}{l}960 \\
(864)\end{array}$ & $\begin{array}{l}1137 \\
(2792)\end{array}$ & $\begin{array}{c}199 \\
(146)\end{array}$ & $<0.0001^{*}$ & $<0.0001^{*}$ & $36 / 47$ & $27 / 34$ \\
\hline
\end{tabular}

Tab. 4. Percentages of values of the various analytes above the upper limit of the respective reference ranges (for fibrin monomer $13.2 \mathrm{nmol} / \mathrm{l}$; for thrombin-antithrombin III $4.1 \mu \mathrm{g} / \mathrm{l}$ and for D-dimer $450 \mu \mathrm{g} / \mathrm{l}$ ).

$\chi^{2}$-test on the numbers showed significance for ${ }^{11} p<0.02 ;{ }^{2)} p<0.05$ and ${ }^{31} p<0.05$

Analytes

(reference ranges)
Percentages of values of the various analytes above the upper limit of the reference range

\begin{tabular}{|c|c|c|c|}
\hline \multicolumn{2}{|c|}{ Cerebral infarction } & \multicolumn{2}{|c|}{ Cerebral haemorrhage } \\
\hline $\begin{array}{l}\text { fatal outcome } \\
(\%)\end{array}$ & $\begin{array}{l}\text { non-fatal outcome } \\
(\%)\end{array}$ & $\begin{array}{l}\text { fatal outcome } \\
(\%)\end{array}$ & $\begin{array}{l}\text { non-fatal outcome } \\
(\%)\end{array}$ \\
\hline 83.3 & 60.0 & $80.3^{11}$ & $28.6^{11}$ \\
\hline 66.7 & 57.5 & 50.0 & 38.1 \\
\hline 83.3 & 77.5 & $100.0^{2)}$ & $66.7^{21}$ \\
\hline $83.3^{3)}$ & $40.0^{3)}$ & 27.3 & 28.6 \\
\hline
\end{tabular}


quencies of occurrence of elevated quantities in the fatal and non-fatal groups were highly significant for fibrin monomers $(80.3 \%$ versus $28.6 \%$ ) in the cerebral haemorrhage patients, for D-dimer in the haemorrhage group (100\% versus $66.7 \%)$ and for the ADPinduced platelet aggregation in the cerebral infarction groups $(83.3 \%$ versus $40.0 \%)$. Neither group showed a significant percentage difference for thrombin-antithrombin III.

\section{Discussion}

The high number of patients taking acetylsalicylic acid (26 out of 81 ) should be noted. Of the remaining 55 patients $21 / 31=67.1 \%$ of the infarction patients and $9 / 24=37.5 \%$ of the bleeding group showed unphysiologically elevated ADP-induced platelet aggregation. These results suggest a systemic increase of hyperaggregable platelets and are concordant with the conclusions of Uchiyama (2) on platelet function in thrombotic cerebrovascular disorders. Taomoto et al. (7) also found indications for platelet activation in cerebrovascular disease by the measurement of the platelet release marker $\beta$-thromboglobulin, and this finding has been confirmed by Fisher \& Francis (8) and Landi et al. (1).

Landi et al. (1) also reported that they could not find significant differences for several haemostatic tests between patients with ischaemic stroke and those with haemorrhagic stroke. In particular, the coagulation and fibrinolysis activation markers, fibrinopeptide A and fibrin degradation products, were not significantly different between the two groups. We tested fibrin monomers (equivalent of fibrinopeptide A), Ddimer (alternative for fibrin degradation products) and thrombin-antithrombin III complex, and we also found no significant differences between the two disease entities for these quantities.

\section{References}

1. Landi, G., D'Angelo, A., Boccardi, E., Candelise, L., Manucci, P. M., Nobile-Orazia, E. \& Morabito, A. (1987) Hypercoagulability in acute stroke: Prognostic significance. Neurology 37, 1667-1671.

2. Uchiyama, S., Takeuchi, M., Osawa, M., Kobayaski, J., Maruyama, S., Aosaki, M. \& Hirosawa, K. (1983) Platelet function tests in thrombotic cerebrovascular disorders. Stroke 14, 511-517.

3. Feinberg, W. M., Bruck, D. C., Ring, M. E. \& Corrigan, J. J. (1989) Hemostatic markers in acute stroke. Stroke 20, $592-597$.

4. van Wersch, J. W. J. (1990) Adaptation and evaluation of a chromogenic test procedure for fibrin monomers on a centrifugal analyzer. J. Clin. Chem. Clin. Biochem. 28, 169174.

5. Pelzer, H., Schwarz, A. \& Heimburger, N. (1988) Determination of human thrombin-antithrombin-III complex in plasma with an enzyme-linked immuno sorbent assay. Thromb. Haemostas. 59, $101-106$.
Fibrin monomers, thrombin-antithrombin III complexes and D-dimers all showed significantly enhanced values in the separate patient groups, compared with the controls. These results are indicative for coagulation activation with' reactive fibrinolysis.

In some cases, activation of the coagulation system was expressed very strongly, Thus in $5 / 47$ patients with brain infarct and in $3 / 34$ patients with cerebral haemorrhage a fibrin monomer concentration of $>30 \mathrm{nmol} / \mathrm{l}$ was measured. Such a situation can be seen as a state of low grade disseminated intravascular coagulation and is concordant with the results on this topic reported by Landi et al. (1).

Moreover we found that the processes of coagulation activation and reactive fibrinolysis can be very long lasting. The prolonged elevation of fibrin monomers, thrombin-antithrombin III and D-dimer concentrations can continue for up to four weeks in some patients (results not shown).

In summary, the results of the present study suggest a state of hypercoagulability after the onset of stroke. Hypercoagulability leads to the formation of thrombin, which is demonstrated by the elevation of fibrin monomer, thrombin-antithrombin III and activated platelets. Whether the haemostatic and fibrinolytic abnormalities preceed stroke and/or possibly contribute to its pathogenesis cannot be concluded from this study. The extent of the necrosis of cerebral tissue might also play a part in the processes after onset of stroke. Nevertheless, the level of hypercoagulability in the first phase after stroke, as shown in the present study, can be considered to be a clinically relevant, negative prognostic factor, as already stated by Landi et al. (1). It therefore appears expedient to determine the haemostatic quantities described in this study in the acute phase of patients with stroke.

6. Amiral, J., Plassart, V. \& Minard, F. (1986) Measurement and Clinical Relevance of D-Dimer by ELISA. In: Fibrinogen and Its Derivates (Müller-Berghaus, G., Scheefers-Borchel, U., Selmayr, E. \& Henschen, A., eds) Excerpta Medica, Amsterdam, pp. 285-290.

7. Taomoto, K., Asada, M., Kanazawa, Y. \& Matsumoto, S. (1983) Usefulness of the measurement of plasma $\beta$-thromboglobulin in cerebrovascular disease. Stroke 14, 518-524.

8. Fisher, M. \& Francis, R. (1990) Altered coagulation in cerebral ischemia. Platelet, thrombin ánd plasmin activity. Arch. Neurol. 47, 1075-1079.

\author{
Dr. J. W. J. van Wersch \\ De Wever Hospital \\ P. O. Box 4446 \\ NL-6401 CX Heerlen ${ }^{i}$ \\ The Netherlands
}

